\title{
Editorial
}

Journal of Innate

Immunity
J Innate Immun 2014;6:713-715

DOI: $10.1159 / 000367718$
Published online: September 10, 2014

\section{The Janus Face of Macrophages in Immunity}

In 1882, Ilya Mechnikov discovered the phenomenon of phagocytosis when he studied larvae of starfishes that were present on small thorns from a tangerine tree that had been prepared for Christmas. The next morning he found the thorns surrounded by the mobile cells. Knowing that when inflammation occurs in animals that have a blood vascular system leukocytes escape from their blood vessels, it occurred to him that these cells might take up and digest bacteria that infest the body [1]. Since their discovery, the knowledge concerning macrophage subsets, functions and roles in health and disease has become comprehensive and sometimes difficult to grasp, in particular for the non-expert. The field became even more complex with the entrance of dendritic cells (DCs). It took Ralph Steinman and Zanvil Cohn [2], who first described DCs in 1973, many years to convince the immunology community that these cells were truly distinct from macrophages. Distinguishing DCs from macrophages is still a matter of debate, and the heterogeneity of the mononuclear phagocyte system was recently reviewed [3].

In this issue, Charles D. Mills and Klaus Ley [4] present an excellent review on the biology of M1 and M2 macrophages, providing perspectives that help to better understand this complex field. Their reasoning centers around inhibit'-type macrophages (M1) can rapidly kill pathogens and are thus primary in host defense while 'heal'-type macrophages (M2) repair and maintain tissue integrity.

Even early forms of life have features of macrophages, for example amoebas that can phagocytose foreign objects but also have the ability to repair [5]. Macrophages are the most numerous leukocytes throughout the animal kingdom and originate from several places including the fetal yolk sac, local renewal, and are also recruited from bone marrow-derived monocytes [6-9]. In the different compartments of the spleen, macrophage populations can be 
found that have distinct functions depending on their localization [10]. It has been discussed whether macrophage and DC responses in tissues are not only dictated by the local environment, but also by newly recruited lineage precursor cells [11]. In lymph nodes, three subsets of macrophages can be identified, i.e. subcapsular sinus macrophages, medullary sinus macrophages and medullary cord macrophages [12].

An important step, profoundly changing our understanding of immunity and also of the roles of macrophages, was the introduction of the innate immune recognition paradigm, in particular Toll-like receptors [13, 14]. As a consequence, crucial roles for macrophages in disease processes have become more and more apparent in recent years. One example is atherosclerosis where changes in macrophage phenotype and function within the atherosclerotic plaque have dramatic consequences for plaque biology, including rupture and arterial thrombosis leading to severe clinical events such as myocardial infarction [15]. Macrophages also have key roles in lung disease. For example in asthma, recent studies show that M2 macrophages are not just bystanders but also active players in orchestrating allergic lung disease [16]. During chronic obstructive pulmonary disease, macrophage subsets develop in response to cigarette smoke exposure [17]. In tuberculosis, neutrophil extracellular traps binding heat shock protein 72 trigger cytokine release from macrophages. This may be important for the interplay between neutrophils and macrophages during the early innate immune phase of tuberculosis infection [18]. Sarcoidosis resembles tuberculosis in that it elicits granulomatous inflammation. It was recently shown that the vitamin $\mathrm{D}$ receptor and the vitamin D receptor coactivator steroid receptor coactivator 3 tumor necrosis factor- $\alpha$-mediated repression of steroid receptor coactivator 3 contributes to alveolar macrophage cathelicidin deficiency in severe sarcoidosis despite normal vitamin D levels [19].

An interesting discovery is that macrophages play an important role in the context of iron homeostasis and host defense where hepcidin is an important molecule [20].

The crucial roles of macrophages in both health and disease become more and more apparent. Therefore, the review by Charles D. Mills and Klaus Ley [4] is important to help us see the clear contours of the macrophage landscape 'as the dust settles'.

Heiko Herwald, Lund Arne Egesten, Lund 


\section{References}

$>1$ Nobel Lectures, Physiology or Medicine 1901-1921. Amsterdam, Elsevier, 1967. http://www.nobelprize.org/nobel_prizes/ medicine/laureates/1908/mechnikov-bio. html.

-2 Steinman RM, Cohn ZA: Identification of a novel cell type in peripheral lymphoid organs of mice. 1. Morphology, quantitation, tissue distribution. J Exp Med 1973;137:1142-1162.

3 Geissmann F, Gordon S, Hume DA, Mowat AM, Randolph GJ: Unravelling mononuclear phagocyte heterogeneity. Nat Rev Immunol 2010;10:453-460.

4 Mills CD, Ley K: M1 and M2 macrophages: the chicken and the egg of immunity. J Innate Immun 2014;6:716-726.

$\checkmark 5$ Cooper EL: Evolution of immune systems from self/not self to danger to artificial immune systems (AIS). Phys Life Rev 2010;7: 55-78.

6 Ginhoux F, Greter M, Leboeuf M, Nandi S, See P, Gokhan S, Mehler MF, Conway SJ, Ng LG, Stanley ER, Samokhvalov IM, Merad M: Fate mapping analysis reveals that adult microglia derive from primitive macrophages. Science 2010;330:841-845.
Schulz C, Gomez Perdiguero E, Chorro L, Szabo-Rogers H, Cagnard N, Kierdorf K, Prinz M, Wu B, Jacobsen SE, Pollard JW, Frampton J, Liu KJ, Geissmann F: A lineage of myeloid cells independent of Myb and hematopoietic stem cells. Science 2012;336:8690.

-8 Jenkins SJ, Ruckerl D, Cook PC, Jones LH, Finkelman FD, van Rooijen N, MacDonald AS, Allen JE: Local macrophage proliferation, rather than recruitment from the blood, is a signature of TH2 inflammation. Science 2011; 332:1284-1288.

-9 Varol C, Yona S, Jung S: Origins and tissuecontext-dependent fates of blood monocytes. Immunol Cell Biol 2009;87:30-38.

10 den Haan JM, Kraal G: Innate immune functions of macrophage subpopulations in the spleen. J Innate Immun 2012;4:437-445.

11 Cortez-Retamozo V, Etzrodt M, Pittet MJ: Regulation of macrophage and dendritic cell responses by their lineage precursors. J Innate Immun 2012;4:411-423.

12 Gray EE, Cyster JG: Lymph node macrophages. J Innate Immun 2012;4:424-436.

13 Janeway CA Jr, Medzhitov R: Innate immune recognition. Annu Rev Immunol 2002;20: 197-216.
14 Beutler BA: TLRs and innate immunity. Blood 2009;113:1399-1407.

15 Williams HJ, Fisher EA, Greaves DR: Macrophage differentiation and function in atherosclerosis: opportunities for therapeutic intervention? J Innate Immun 2012;4:498-508.

16 Dasgupta P, Keegan AD: Contribution of alternatively activated macrophages to allergic lung inflammation: a tale of mice and men. J Innate Immun 2012;4:478-488.

17 Lee JS: Heterogeneity of lung mononuclear phagocytes in chronic obstructive pulmonary disease. J Innate Immun 2012;4:489-497.

18 Braian C, Hogea V, Stendahl O: Mycobacterium tuberculosis-induced neutrophil extracellular traps activate human macrophages. J Innate Immun 2013;5:591-602.

19 Barna BP, Culver DA, Kanchwala A, Singh RJ, Huizar I, Abraham S, Malur A, Marshall I, Kavuru MS, Thomassen MJ: Alveolar macrophage cathelicidin deficiency in severe sarcoidosis. J Innate Immun 2012;4:569-578.

20 Ganz T: Macrophages and systemic iron homeostasis. J Innate Immun 2012;4:446-453. 